\title{
Significance and Status Quo of the Localization Development of Ethical Value of Social Work
}

\author{
Wang Dandan \\ Jiangxi civil affairs school \\ 98 Dingshan Road, Qingyunpu District, Nanchang City, Jiangxi Province
}

\author{
Keywords: Social Work; Ethical Value; Localization
}

\begin{abstract}
At present, our country is on the transition period, so our politics, economy and culture have undergone earth-shaking changes, and social problems crop out constantly, and more and more people need assistance, while traditional methods can hardly meet China's demand. Social work is a kind of profession that helps people to help themselves and is of great value. At the same time, it is also a profession that features social ethics. After being introduced in China, social work has gained certain progress, but it inevitably confronts some complex situations and all sorts of ethical issues in the process. Ethical value occupies a crucial strategic role in terms of social work, and is regarded as the soul and core, and is also influenced by our traditional culture, social environment and other factors. There exists a certain discrepancy between ethical value of social program and the system of ethical value in western social program, which is incompatible with the reality. However, the most direct solution to this problem is to localize the ethical value of social work. Based on this point of view, the author will, by combining his own experience, study the localization of ethical value in social program from the perspective of sociology, and first elaborate on the localization of ethical value in social program and its development significance, and then analyze its plight in reality.
\end{abstract}

\section{Introduction}

Social work stems from western European countries, and wasn't introduced into China until the first half of the 20th century. It is a profession, responding to the demand of an individual and the society in the development, and turning into the social work, which exerts an irreplaceable role on the social progress. Since the reform and opening-up in 1978, China's society has entered the phase of transition. Social work has accordingly changed. Among different historical background, development stage, systems and cultural backdrop, requirements towards social work are not the same. As a specialized service, it has various paths to the development under different institutional cultural background. Copying western ethical value of social work can hardly meet the actual requirements of social progress. As we all know, the localization is a trend that deserves all of our efforts.

\section{Notion}

Social work is a profession and an occupation, tackling the demands of an individual and the society in the course of the development. It was once introduced from the West, and it confronted plenty of problems and plights amid the development. However, "localization" is the most fundamental solution to the existing problem of social work.

To this end, the first step is to make a definition for relevant concepts regarding the localization of ethical value of social work. Ethics and value are the core of social work, while the ethical value of social work is based on it, which mainly claims ethical standards and principles of social work profession and social worker. Specifically, ethical value of social work is firstly social workers' standards of ethical value. Secondly, it is the required standards and principles of social workers in social work. Finally, it is the ethical value standards about profession and occupation of social worker, which reflects the quality of social work, so as to distinguish it with others. Moreover, it can be used as a proof to tackle and address professional disputes. In conclusion, ethical value of social work is the specific form of social work value, and it is operational, which brings the advantages of promotion, 
regulation and limit in the process of social work, and provides references [1] for social workers when they face all types of ethical problems in social work. Remarkably. Ethical value of social work isn't unchanged. On the contrary, targeted subjects and elements will change in accordance with the development of the society and the times.

The ultimate settlement of the ethical value of social work developing in China is to localize. The term "localization" gained popularity in 1960s and 1970s, mainly indicating that best practice and effective methods are introduced into China, and coordinate it with our national reality [2]. Localization is a process, based on learning foreign philosophy, ways and experience, but focusing on domestic situation, in search of the common factors between foreign cutting-edge methods and domestic culture, which is used to integration. Therefore, it will promote its indigenous characteristic. However, the localization of the ethical value of social work is based on learning from the western countries' ethical value of social work, so as to find out the interlinked ideas between our traditional culture and the western's counterpart. In addition, through the previous best practice of the skilledhelper model, we aim to build the ethical value of social work featuring Chinese characteristics.

\section{Significance}

Localization of ethical value in social work is of great benefit. First, it makes social work available to the society. Currently, our country stays at the period of transition, with the emergence of countless social problems. Also, uneven regional economic growth results in a wider gap between the rich and the poor. And for years, natural disasters and social accidents take place frequently, making it possible that more social rescues and aids are increasingly required [3]. Social work can provide professional support in the social progress. When it was introduced into China, a large number of conflicts and problems occurred in the development, which escalates the difficulty to serve the society. Yet localization development is the chief method, which can meet the needs of the society for social work. Second, it is the irreversible trend to follow the localization of ethical value in social work amid social progress. If we hope that social work serves Chinese society, the prerequisite is to adapt it to our society. As the saying: "Do as the Romans do", it should be rooted in our homeland if the system of ethical value in social work from the West improves in China. Then, both Chinese cultural and social ethics, and western ethics of social work should be integrated together, which can further make progress, and spread its influence on China's society. Third, localization can build an ethical system of social work that features Chinese characteristic and suits social progress in China. The deepening globalization, influx of western culture, and the influence of modern culture, all of which give rise to the assimilation of Chinese culture and are extremely erosive. After the social work implemented, certain effect can be witnessed necessarily. The combination of Chinese culture and social work philosophy will be bound to build a ethical system of social work featuring Chinese characteristic and a strong adaptation to China's social progress.

\section{Development status}

Localization of ethical value in social work, in fact, means the integration of Chinese and western culture, mainly including such elements as ethical value of western social work ethical value of traditional Chinese culture, and the view of cultural value which plays a predominant role in China. With regard to the first element, learning and innovation are required. The second and the third of them should be inherited through the critical judgment and vice versa. Today, the reality of the localization of ethical value in China's social work confronts the hardship to integrate these three elements altogether.

\subsection{Learn from the system of ethical value from western social work}

As social work forges ahead, nowadays, western European countries have already boasted the sophisticated system of ethical value in social work, while China needs to learn from its merit. At present, there are two viewpoints in the academic society for the learning of the social work ethical value system of the western society. One is the theory of Chinese culture in western use. The other is 
the theory of western culture in Chinese use. Both vary greatly in terms of content and direction of study [4]. The former mainly focuses on the ethical value of Chinese society, giving the ethical value of western social work the second place. It is also known as give priority to of the ethical value of traditional Chinese culture, combined with methods and techniques of western social work. The latter is opposite. [5]

Moreover, the content and methods concerning the system of ethical value in western social work should all be studied. Academic fields mostly study the system's source, principles, etc. However, they lack the systematic research in the system. It is instructive for academic fields to believe that the content mainly includes the principles of ethical value in western social work, with regard to the content of ethical value system of western social work. Therefore, when learning from the principles [5] of ethical value of social work in the western society, it is crucial to focus on the code of ethic values. Nonetheless, the ethical value system of western social work is systematic and giant, and the code of ethical value is an important component with extraordinary performance, and it is a predicament for us to explore its ideology and essence through the shallow surface, which needs to be addressed and absorbed. We can only drive the building of the system of ethical value in social work with Chinese characteristic by understanding the system in a comprehensive and specific way, and absorb its essence in various aspects.

\subsection{Absorb Chinese culture}

After social work was introduced into China, localization development is an inevitable trend, and its premise is to adapt to the needs of local society, so it is necessary to absorb and learn from local culture. Chinese culture mainly includes the ethical thought experience and the contemporary social ethics thought contained in the culture, but there are also some difficulties in the process of learning from them.

First of all, social work enjoys less popularity in China, with regard to the problems in absorbing the ethical thoughts and experiences contained in the culture. Most of the social members do not have a thorough understanding of social work and are deeply influenced by traditional culture, such as the concept, "family troubles are not a thing to be discussed in public". Even when they encounter difficulties or problems, they would rarely take the initiative to seek for help, which, to a certain extent, escalates the difficulty of practicing social work in China. In addition, the development of social work in our country is late and enjoys only a short period of time, and neither the content nor the system is professional enough, and there are few practical positions provided by the society, which will also affect the construction and practice of localization of ethic value of social work. Meanwhile, for academic fields, it also hinders the research on the localization of ethic value of social work, which is not conducive to its smooth implementation and progress[6]. The localization of ethnic value of social work aims to serve Chinese society, so it will be difficult to verify whether the results of the localization of ethical value of social work are feasible and promote social work to better serve the society without practice.

In addition to this, since there are few social workers in China, it is difficult to timely reflect the problems existing in the process of social work. As a profession, social work has strong specialization and practicality. At present, there is a shortage of professionally trained social workers in China's social work, so lacking professionalism and practicality makes it difficult in finding and reporting problems in social work, and thus affects the progress of the localization of ethical value of social work. In addition, there are few researches and empirical evidences on the localization of ethical value of social work, the main reason is that the academic circles don't pay much attention to it and without reaching a consensus, which lead to duplicate research, waste academic research resources and hinder localization of ethical value of social work.

In view of the problems in absorbing contemporary Chinese social ethics, the ethics and value of social work are not fixed and unified, Instead, it changes in accordance with the times, and ethical value represents age feature. Therefore, it is necessary to incorporate the ethical thought with the characteristics of the times into the localization of ethic value of social work. However, people can't unify the definition of contemporary social ethics, and they are not clear about what is reasonable and 
what is not. Moreover, there are insufficient amount of researches in this aspect and the concept about it is still relatively vague.In addition, contemporary social ethics have a broad, various, specific and profound content and many schools, including family ethics, political ethics and cultural ethics, so it is difficult to analyze it comprehensively, find the dominant social ethic, and discover the essence through the ethical phenomenon, which directly affects localization of ethic value of social work.

\section{Conclusion}

In conclusion, social work was introduced into China from western countries, Localization is the inevitable trend of its long-term development in China, and it can well meet the actual needs of individuals and society. Localization of ethical value of social work deserves the reference of ethical system in western social work as well as the criticism and inheritance of Chinese culture and the corresponding and common points should be found. If so, all of what we have done can contribute to the development which suits our interests.

\section{Acknowledgment}

The research was not funded

\section{References}

[1] SHI C, YUAN XJ. Localization of professional social work and specialization of local workTwo drivers for the development of social work in China. Social work and management, 19(05): 76-82, 2019.

[2] YAN QY. The localization practice and service suggestion of eight principles of evidence-based correction--Take caritas community correction service as an example. Chinese journal of drug abuse prevention, 25(05): 287-290, 2019.

[3] YE XR. Review and reflection on the localization of international social work--on the enlightenment of localization of social work in China, urnal of East China University of Science and Technology (social science edition), 34(04): 1-13+25, 2019.

[4] YU HL, HE QS. The basic connotation and promotion path of the healthy development of professional social work in China under the background of the new era, cial work and management,19(03): 64-70, 2019.

[5] WANG YA, YAN FY, ZHANG H, CHENG JQ. Our country's current situation, hot spot and trend in social work research -Based on bibliometrics and knowledge map analysis from 1998 to 2017 of CSSCI database, Chinese social work research, (02): 196-214+225,2018.

[6] CHEN LD. Ethical value of social work in community service for aged, Intelligent Information Technology Application Association. Information, Communication and Education Application (ICEA 2011), Intelligent Information Technology Application Association: Intelligent information technology application society, 4.2011. 